\title{
A six year longitudinal study of the occupational consequences of drinking over "safe limits" of alcohol
}

\author{
Rachel Jenkins, Sharon Harvey, Tony Butler, Ruth Lloyd Thomas
}

\begin{abstract}
Although much research has focused on the psychological, social, and economic consequences of heavy problem drinking, there has been far less attention paid to the consequences of "moderate" drinking. This study used a unique opportunity to carry out a six year follow up of a cohort of male and female white collar workers in whom there was baseline information on alcohol consumption and access to details on sickness absence, labour turnover, and promotion. It has provided evidence that even moderate alcohol consumption in the working population is associated with social costs for the employer and the employee, including substantial sickness absence, and lack of promotion in men, although the increase in labour turnover was not statistically significant. The longitudinal examination of consumption in this study suggests that early intervention in a drinking career may reduce alcohol consumption and consequently avoid years of morbidity and sickness absence, as well as having a favourable influence on performance and labour turnover.
\end{abstract}

Alcohol consumption has been increasing rapidly in most parts of the world. The production of beer, wine, and spirits is relatively easy and so the limits of production are largely determined by the capacity of the market for consumption. It is clear that alcohol has become cheaper in terms of disposable income, with a labourer needing to work for six and a half

Institute of Psychiatry, Denmark Hill, London SE5 $R$ Jenkins

The Psychiatric Hospital, Black Rock, St Michael, Barbados

S Harvey

Centre for Research in Drugs and Health Behaviour, North West Thames RHA

T Butler

Civil Service Medical Advisory Service

R Lloyd Thomas hours for a bottle of whisky in 1950, whereas thirty years later he need only work for two hours. ${ }^{1}$

Good evidence exists for an association between alcohol consumption and cirrhosis of the liver ${ }^{23}$ and in particular it has been noted that during times of prohibition the incidence of cirrhosis falls. ${ }^{1}$ The susceptibility of persons to alcohol induced liver damage varies but women appear to be at greater risk than men. ${ }^{45}$

Medical, political, and industrial attention is often focused on "problem" drinkers, as these are relatively visible in the workplace, with a sickness absence five times that of the average, and are three times more likely to have accidents at work. ${ }^{6}$ The "moderate" drinkers, who are in the majority, are often ignored, however, despite the evidence that moderate drinking is associated with accidents and absenteeism that add to the cost of alcohol consumption in the community. ${ }^{7}$ It is estimated that alcohol abuse and alcoholism cost the United States nearly $\$ 43$ billion in 1975 , including $\$ 19.64$ billion in lost production, $\$ 5 \cdot 14$ billion in motor vehicle accidents, and $\$ 2.86$ billion in violent crimes. ${ }^{7}$ In the United Kingdom costs have been estimated at $£ 1.6$ billion in 1985 and $£ 2$ billion in $1987 .{ }^{89}$ This documentation of costs is an important step in the campaign to reduce the incidence of alcohol related deaths, morbidity, and health care costs.

A recent United States community survey indicated that there are substantial proportions of employed men and women with alcohol problems even among groups not hitherto considered to be at high risk for problem drinking. ${ }^{10}$ These social and research trends underline the need for urgent reassessment of what might be considered a "safe" quantity of alcohol for either sex, in terms of associated physical and psychological morbidity, occupational problems such as sickness absence, labour turnover, impaired performance at work, and impaired attitudes to work as well as in terms of other social problems for the person and the family.

The determination of safe limits is complicated by reports that low amounts of alcohol may have beneficial effects, such as the decrease in mortality from 
ischaemic heart disease. ${ }^{11}$ It has been found, however, that this group is less likely to smoke and to contain manual workers, ${ }^{12}$ suggesting that these variables may contribute to the finding. This is by contrast with reports of the risk of an increased morbidity at concentrations of 16 units a day..$^{13}$ The question of "safe drinking" is often raised by the public, and the Royal College of Psychiatrists ${ }^{14}$ the Royal College of Physicians, ${ }^{15}$ and the Health Coun$\mathrm{cil}^{16}$ have published guidelines. These suggest that up to 14 units of alcohol a week for a woman, and up to 21 units a week for a man would be safe levels whereas over 35 units a week for a woman or 50 for a man would definitely be harmful.

This study provided a unique opportunity to carry out a six year follow up of a cohort of male and female white collar workers in whom there was baseline information on alcohol consumption and access to details on sickness absence, promotion, and turnover of labour. Although the sample size is small, detailed intensive data are available.

\section{Method}

\section{STUDY POPULATION}

A cohort of direct entrant executive officers in the Home Office, previously assessed by one of us (RJ) in 1980 and 1981, were the subjects of the present follow up study carried out in $1986-7 . .^{17-20}$ Direct entrant executive officers all have either $A$ levels or university degrees and are selected on the basis of a civil service examination, with no job allocation on the basis of sex. Eligibility for promotion to higher executive officer occurs after four years of service and to senior executive officer after three years of service as higher executive officer. In practice, promotion occurs after much longer periods of service.

\section{METHODS OF ASSESSMENT}

\section{Assessment of alcohol consumption}

Respondents were asked to quantify their alcohol consumption for the seven days before interview. This was categorised into beer, wine, and spirits, with note taken of the average amount of alcohol consumed at a sitting and the number of sittings in the previous seven days. This was converted to units of alcohol (one unit $=7.9 \mathrm{~g}$ pure alcohol). The analyses in this paper are based on the published "safe limit."

\section{Assessment of sickness absence}

Information on the certified and uncertified leave of executive officers was available from the Establishment Department of the Home Office, which keeps details both in terms of spells and days. In 1982 a change of policy allowed the first seven days of any spell of leave to be self certified. This information was extracted over the years 1982-6, and data for the years 1972-82 were already available from the previous study.

\section{Results}

DEMOGRAPHIC STRUCTURE OF STUDY POPULATION

By 1986 the 1980 cohort, which had consisted of roughly 80 women and 104 men, average ages 27 and 26 respectively, had dwindled to only 24 women and 51 men with average ages of 32 and 33 . Repeated efforts to trace the remainder failed and they were assumed to have left the Home Office. After this time, however, personnel records at the Home Office were computerised and a subsequent visit at the end of 1990 identified a further 21 respondents who had not in fact left, making a total sample of 30 women and 66 men, again with average ages of 32 and 33 . It was clearly not possible to ascertain the psychiatric score and alcohol consumption of these 21 people for 1986, but it was possible to obtain sociodemographic details and occupational state for 1986, together with sickness absence for the period 1980 to 1986 . These data are therefore included in figures where relevant. Figure 1A compares the educational state, as elicited in 1980, of those employees who stayed in the Home Office until 1986 compared with those who left the Home Office between 1980 and 1986. There were fewer honours degrees among women who left compared with those who stayed and for men the reverse was true. Taken in association with the findings that proportionately more single men and married women in the group had left by 1986 (see fig 1B), this supports the widely held view in the Home Office that in general women leave to start a family whereas men leave to go to better job opportunites elsewhere.

\section{ALCOHOL CONSUMPTION AND PROMOTION}

In 1980 all the sample were executive officers. By 1986 some had been promoted to higher executive officers and senior executive officers. It is of interest to note that the quantity of alcohol consumed in the week before interview was associated with occupational state in 1986 but in opposite directions for each sex so that the alcohol consumption of men decreased with promotion, whereas that of women increased (fig 2).

\section{ALCOHOL CONSUMPTION AND SICKNESS ABSENCE}

The relation of sickness absence to alcohol consumption over the period 1980 to 1986 was examined by comparing the summed sickness absence between those who consumed low quantities of alcohol in both 1980 and 1986 with those who drank higher quantities at either time or both times. A cut off point of 14 units a week was used for women and 21 units a week for men. Figure 3 shows that in women no significant pattern emerged although certified days and total days were doubled in women drinking more than 14 

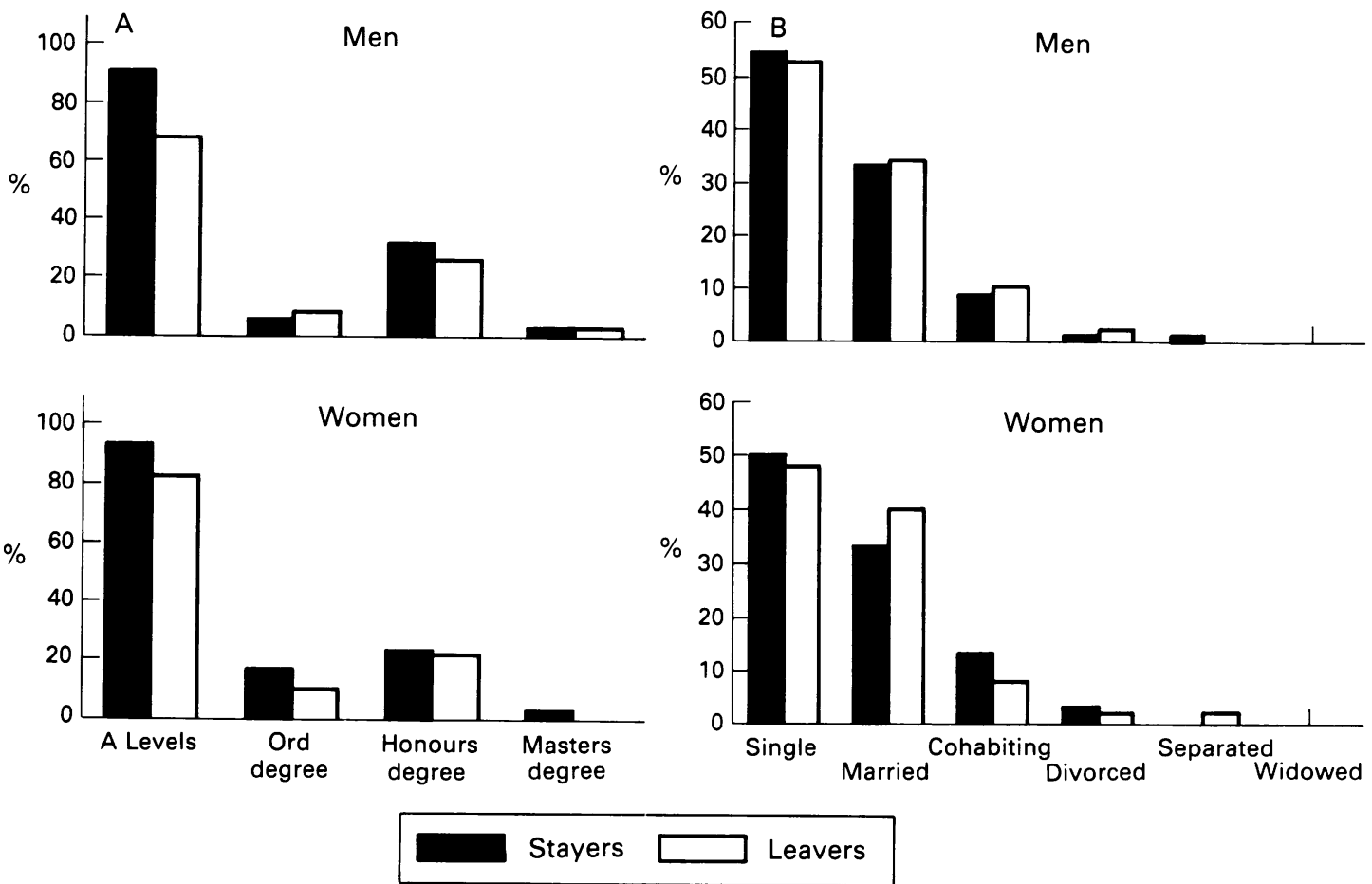

Figure 1 A, comparison of educational state of male and female "stayers" and "leavers"; B, comparison of marital state of male and female "stayers" and "leavers".

units a week compared with those drinking less; in men, those drinking over 21 units of alcohol a week consistently took more certified and uncertified leave. Also the number of uncertified spells and certified days taken just failed to be significant, whereas men drinking over 21 units a week took consistently and significantly more total spells of sickness absence. This figure excludes data on 21 people who were subsequently identified as "stayers", but whose alcohol consumption in 1986 is not known.

\section{ALCOHOL CONSUMPTION AND LABOUR TURNOVER}

Using the estimation of alcohol intake obtained in the previous study, those remaining in the Home Office were compared with those who had left.

Those who left the Home Office between 1980 and 1986 had a higher mean alcohol consumption in the week before interview in 1980 than those who remained in the Home Office. This was not statistically significant (fig 4).

\section{Discussion}

More women than men left the Home Office between 1980 and 1986, making the cohort smaller than was hoped, and biased towards men. Furthermore, there were demographic differences between the men and women who left, further biasing the cohort. More married women left than married men, and more highly educated men (with honours and masters degrees) left than did highly educated women. None the less it seemed worth proceeding despite small numbers because of the uniqueness of the data set and the detailed information available.

\section{ALCOHOL CONSUMPTION AND WORK}

Alcohol consumption in the working population can cause social problems and social costs both for the employer and the employee. ${ }^{821}$ For the employer, there is lateness, sickness absence, and poor productivity and even staff turnover, and for the employee, problems may include loss of pay and promotion.

It has long been known that heavy alcohol consumption is related to sickness absence. When working people attending alcohol treatment centres were investigated, between 50 and $98 \%$ admitted that they had lost days from work due to their drinking. ${ }^{223}$

By contrast, our present study considered the relation of relatively moderate alcohol consumption and sickness absence, and found that men drinking over 21 units of alcohol a week in both 1980 and 1986 

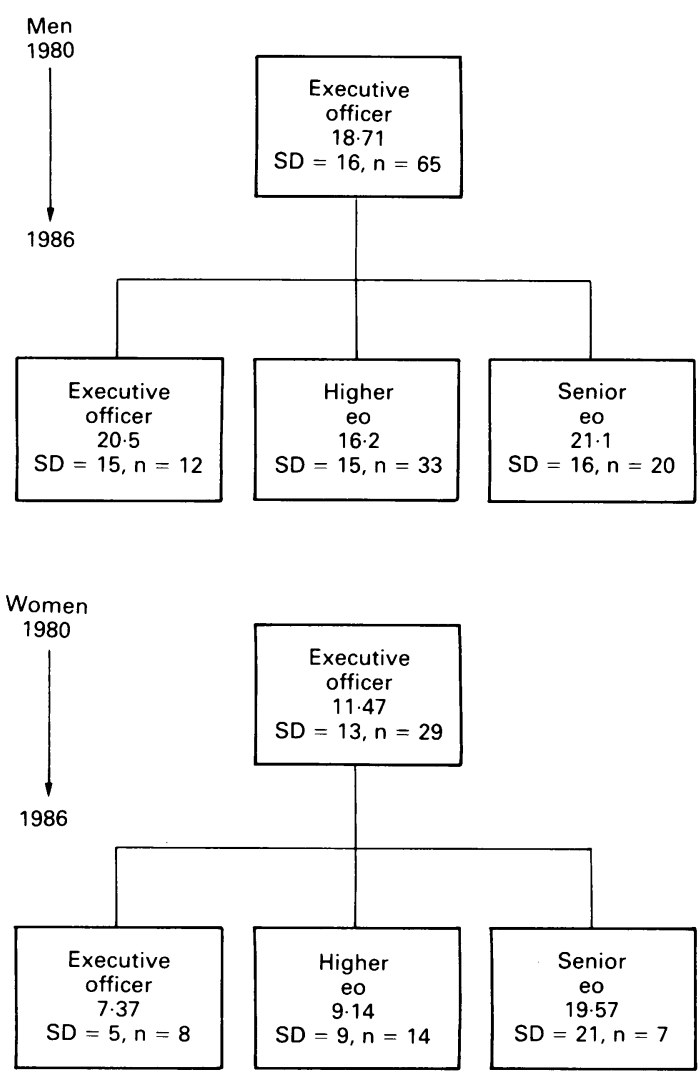

Figure 2 Mean alcohol consumption (units) in past seven days and promotion to higher occupational grade.

took twice as much absence, measured in both total episodes (spells) and total duration (days) as men drinking less than 21 units of alcohol. The corresponding safe limit for women is 14 units of alcohol a week, but at this threshold, no consistent pattern of excess sickness absence emerged.

Previous studies of the relation of alcohol intake to sickness absence have been based on self reporting of sickness absence. It is an important feature of this study that the measurement of sickness absence is objective, based on accurate data collected routinely on a longitudinal basis by the Civil Service, and includes spells and numbers of days of both certified and uncertified absence.

We had access to the general practitioners' diagnoses for certified absence, and the subjects' given reasons for uncertified or self certified absence. It is of interest, although not surprising, that none of the given diagnoses for sickness absence in the present study included overt alcohol problems. It is now well understood that attempts to ascribe a spell of absence to a single particular cause ${ }^{24}$ do not recognise the multifactorial social, physical, psychological, and cultural causes of absence ${ }^{25}$ and such attempts are likely to significantly underestimate the overall impact of a variable such as alcohol consumption on absence from work.

This study also found an association between alcohol consumption and promotion. Women who had been promoted to a senior position by $1986 \mathrm{drank}$ much more than those who had not been promoted, whereas the reverse was true for men. A similar situation was found by Parker $e t a l^{10}$ who showed that female managers and administrators had increased rates of non-dependent problem drinking compared with labour and service workers, but the reverse was true for men. The explanations for this are not known, but it could be that men with a higher alcohol consumption are less likely to get promoted, whereas women start to drink more under stresses that follow promotion. Perhaps women in the Civil Service find promotion more stressful than do men. Certainly there are proportionately far fewer women in senior positions in the Civil Service than their $50 \%$ entry at executive officer level.

The relation found between alcohol consumption

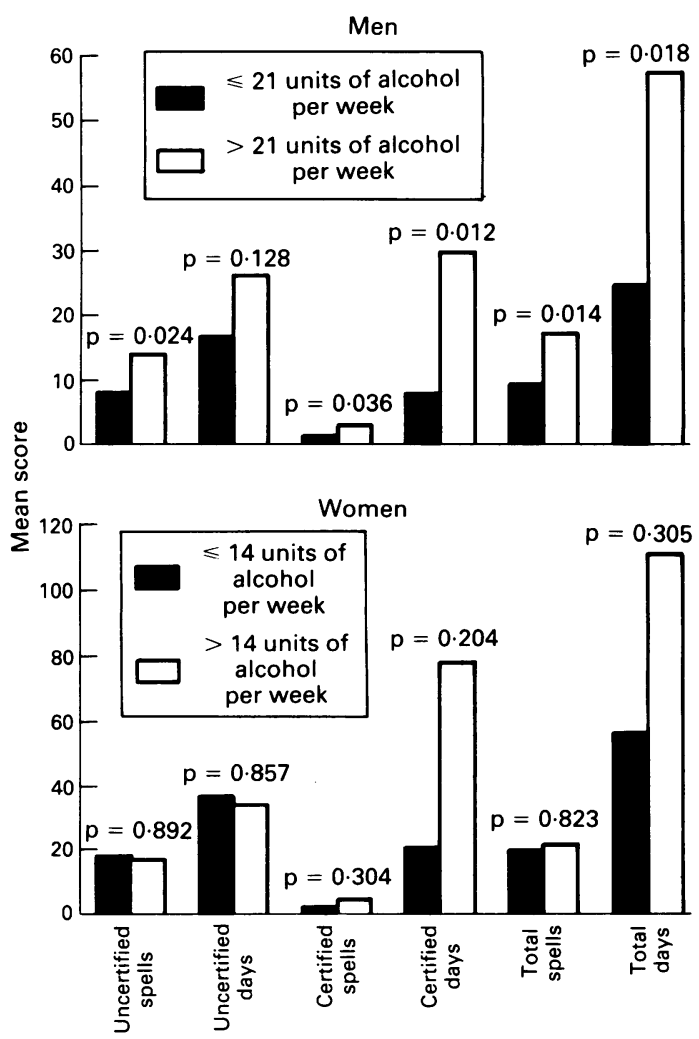

Figure 3 Sickness absence and alcohol consumption: men and women. 


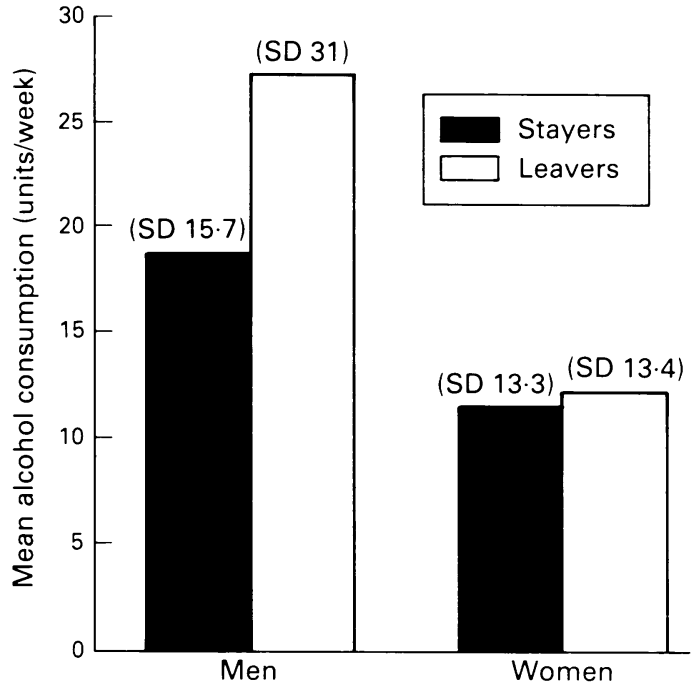

Figure 4 Labour turnover and alcohol consumption.

and turnover of labour was not statistically significant although the trend was that those subjects who subsequently left the Home Office had higher intake of alcohol in 1980 than those who remained. The cost of recruiting and training replacements is substantial and this relation needs to be explored further.

\section{Conclusions}

This study has provided evidence to support the view that even moderate alcohol consumption in the working population is associated with social costs for the employer and the employee including substantial sickness absence and lack of promotion in men, although the slight increase in labour turnover was not statistically significant. Whereas education programmes about alcohol in the workplace are slowly being implemented, these tend to concentrate on heavy consumption, and the risks associated with moderate consumption have hitherto been unrecognised. The longitudinal examination of consumption in this study suggests that early intervention in a drinking career may reduce alcohol consumption, consequently avoid years of morbidity and sickness absence, and have a favourable influence on promotion prospects and labour turnover. We should not only rely on workplace initiatives; a need also exists for a wider initiative, based on general practice, to advise and counsel young people about the risks of alcohol consumption, and to provide help to reduce consumption. Early reports of the efficacy of such initiatives are most encouraging. ${ }^{26} 27$
Requests for reprints to: Dr Rachel Jenkins, MD, Honorary Senior Lecturer, Section of Epidemiology and General Practice, Institute of Psychiatry, Denmark Hill, London SE5.

This study was supported by grants from the Mental Health Foundation and the Wellcome Trust. We are grateful to the Civil Service Medical Advisory Service, the Home Office Establishment, the Staff Society, and the individual executive officers without whose wholehearted cooperation the study would not have been possible. Special thanks are due to Miss Margaret Clayton, $\mathrm{Mr}$ Tony Rawsthane, and $\mathrm{Mr}$ Tim Flescher for their advice and help in carrying out the study, and to Miss Christine Stimson for practical assistance in obtaining sickness absence records. We are grateful to Professor Griffith Edwards, Dr John Reed, Dr John Shanks, and Dr Dilys Jones for helpful comments on earlier versions of this paper.

1 Kendall RE. Alcoholism: A medical political problem. $B M J$ 1979;5:367-71.

2 Skog O. Interpreting trends in alcohol consumption and alcohol related damage. Alcohol and Alcoholism 1988;23:193-302.

3 Lederman S. Alcool, alcoolisme, alcoolisation. Paris: Institut d'Etudes Demographiques, 1956.

4 Dunne F. Are women more easily damaged by alcohol than men? Br J Addict 1988;83:1135-6.

5 Beary M, Merry J. The rise in alcoholism in women in fertile age. Br J Addict 1986;81:142. (Letter.)

6 Tether P, Robinson D. Preventing alcohol problems-a guide to local action. London: Tavistock, 1986;151.

7 Grant M, Ritson B. Alcohol-the prevention debate. London: Croom Helm, 1983.

8 McDonnell R, Maynard A. The costs of alcohol misuse. $\mathrm{Br} J$ Addict 1985;80:27-35

9 Maynard A, Hardman G, Whelan A. Date Note 9. Measuring the social costs of addictive substances. $B r$ J Addict 1987; 82:701-6.

10 Parker DA, Kaelber C, Harford TC, Brody JA. Alcohol problems among employed men and women in Metropolitan Detroit. J Stud Alcohol 1983;44:1026-39.

11 Marmot MG, Rose G, Shipley MJ, Thomas BJ. Alcohol and mortality: 'U' shaped curve. Lancet 1981;i;580-3.

12 Shaper AG, Phillips AN, Pocock SJ, Walker M. Alcohol and ischaemic heart disease in middle aged British men. BMJ 1987;294:733-7.

13 Tuyns AJ, Pequinot G. Greater risk of ascitic cirrhosis in females in relation to alcohol consumption. Int J Epidemiol 1984; 13:53-7.

14 Royal College of Psychiatrists. Alcohol: our favourite drug. London: Royal College of Psychiatrists, 1986.

15 Royal College of Physicians. A great and growing evil: the medical consequences of alcohol abuse. London: Tavistock, 1987.

16 Health Education Council. That's the limit: a guide to sensible drinking. London: Health Education Council, 1984.

17 Jenkins R. Sex differences in minor psychiatric morbidity in employed men and women. Psychological Medicine 1985. (Monograph Suppl No 7.)

18 Jenkins R. Minor psychiatric morbidity in employed young men and women, and its contribution to sickness absence. $\mathrm{Br} J$ Ind Med 1985;42:147-54.

19 Jenkins R. Minor psychiatric morbidity and labour turnover. $\mathrm{Br}$ $J$ Ind Med 1985;42:534-9.

20 Jenkins R. Sex differences in alcohol consumption and its associated morbidity in young civil servants. $\mathrm{Br} J$ Addict 1986;81:525-35. 
21 Crofton J. Extent and costs of alcohol problems in employment: a review of British data. Alcohol and Alcoholism 1987;22: 321-5.

22 Glatt MM, Hills DR. Occupational behaviour patterns in samples of English alcoholic employees. Br J Addict 1965; 61:71-8.

23 Edwards G, Guthrie S. A controlled trial of in-patient and outpatient treatment of alcohol dependency. Lancet $1967 ; \mathrm{i} \cdot 555-9$.

24 Casswell S, Gilmore L, Ashton T. Estimating alcohol-related absenteeism in New Zealand. Br J Addict 1988;83:677-82.

25 Johns G, Nicholson N. The meanings of absence: new strategies for theory and research. In: Staw BM, Cummings LL eds. Research in organisational behaviour. Greenwich CT: JAI Press, 1982.

26 Kristenson $\mathrm{H}$. Methods of intervention to modify drinking patterns in heavy drinkers. Rec Dev Alcohol 1987;5:403-23.

27 Chick J, Lloyd G, Crombie E. Counselling drinkers in medical wards: a controlled study. BMJ 1985;290:965-7.

Accepted 16 September 1991 